\title{
Millimole per Minute per Thousand Pascal per Liter
}

National Cancer Institute

\section{Source}

National Cancer Institute. Millimole per Minute per Thousand Pascal per Liter. NCI

Thesaurus. Code C67423.

A SI-coherent unit for measuring a pulmonary diffusing capacity adjusted for lung volume and expressed in units of a substance flow rate (in millimoles per minute) per unit of pressure (in kilopascals) per unit of alveolar volume equal to one liter. 